literature and geopolitics of the Antarctic in prose that is at times powerful but also, over 400 pages, can occasionally be fatiguing.

It is The Ice, the forces which create and destroy it and the forces which it in turn influences, that dominate the book. Because over 60 per cent of the world's fresh water is locked into the Antarctic, and tabular bergs the size of Belgium are not uncommon, perhaps this preoccupation is understandable, if not particularly stimulating for the reader.

It is only where man makes an appearance, and the ice terranes and ice orrerys are relegated temporarily to the background, that a wider perspective becomes apparent. Pyne develops the thesis that The Ice imposed on explorers, as on artists, the need to develop not only special technologies but also to adopt new casts of thought. These concepts are analysed and expanded at some length in the book, but the result seems to offer little of substance

\section{When dark is light enough}

\section{Owen Gingerich}

Darkness at Night: A Riddle of the Universe. By Edward Harrison. Harvard University Press: 1987. Pp. 293. \$25, £19.95. "A GREAT cause of the night is the lack of
the Sun", says the innocent shepherd in $A s$
You Like It, and though we may chuckle
at his naiveté, few of us stop to ponder the
more profound alternative. "A great
cause of the darkness at night is the lack of
Suns". If the Universe is infinite and
randomly filled with stars, then any line
of sight must eventually reach a star,
and the vault of the heavens should be
aglow with the brilliance of an average
star's surface.

If you are convinced that the Universe is infinite and randomly filled with brightly shining stars (or galaxies of stars), then the darkness is a paradox. But if you believe that the Universe is either limited or not randomly filled with stars, then the darkness is a riddle to be solved. Hermann Bondi, who in the early 1950s accepted an infinite steady-state Universe, popularized the problem as "Olbers" paradox". He claimed that the red shift of the distant galaxies solved the puzzle, and that earlier astronomers could have deduced the idea of the expanding Universe merely from the darkness of the sky at night.

Since Bondi's Cosmology, "Olbers' paradox" has been part of the astronomers' vocabulary, and the problem of darkness at night has been the subject of to the scientist, and the humanistic perception, with which the author is credited on the jacket, although evident may well confuse the layman.

The author claims to have found in the Antarctic ice, "from core to margin, from polar plateau to open sea an allegory of matter". His thoughts about his allegorical discovery in, and return from, the icy vastness of the Antarctic seem to be encapsulated in the lines he quotes from Edgar Allen Poe's "Dreamland":

I have reached these lands but newly From an ultimate dim Thule

From a wild weird clime that lieth sublime Out of SPACE and out of TIME.

The space and time of the hauntingly beautiful Antarctic are there to be glimpsed in this, the author's own dreamland.

Derek Fordham, 66 Ashburnham Grove, Greenwich, London SE10 8UJ, UK, is Secretary of the Arctic Club and has travelled widely in polar regions.

The prize goes - somewhat ambiguously - to the remarkable insight of Edgar Allen Poe and to the independent and nearly forgotten calculations by Lord Kelvin. Harrison has resurrected both of these accounts, and he accepts their answer: stars simply do not shine long enough for there to be the necessary infinite number to dazzle the night-time sky. He describes how the Bondi-Gold redshift solution would indeed work for a steady-state cosmology but not for the bigbang model. At the last stop on the tour, Harrison recasts the Poe-Kelvin solution into a somewhat different form in order to show that there is an even better way to look at the problem. There simply is not sufficient energy in the Universe for the stars at night to be so many and bright.

As a cosmologist, Harrison seems to have withstood the critical examination of his peers, for his solution has appeared without refutation in technical journals. The extensive bibliography as well as the success of his detective work attests to his skills as a historian of science. But the swift, nutshell descriptions of astronomers of yore will give chills to sterner, more professionalized historians. I found the chaotic inconsistency of book titles, sometimes in their original tongues and sometimes in translation, rather careless, and I was distressed that an appendix devoted to "Digges on the Infinity of the Universe" nowhere states that this is, except for one small but crucial part, merely Digges's translation from Copernicus. And to label as "Stoic" any astronomer who accepted a bounded system of stars within unlimited empty space - such as Harlow Shapley in 1920 - is less than helpful.

Harrison is quite forgiving that Bondi popularized the "riddle" under the misnomer "paradox", and that he assigned it to Olbers instead of Cheseaux, who had specified the problem earlier. Indeed, Olbers had Cheseaux's book in his library, but must have forgotten about the Swiss astronomer's account of 1744 when he wrote his own paper in 1823 . Referring to Bondi, Harrison says, "Encumbered with one or two trifling historical inaccuracies, the riddle gained a new lease on life". His relaxed attitude may now stand him in good stead: since this book went to press, Frank Tipler has shown that Poe's solution of the riddle was given even earlier by the selenographer Johann Heinrich Mädler, and even that Poe knew of Mädler's speculations on this subject. Such are the pitfalls in an attempt at historical completeness! Nevertheless, Harrison's tour is nearly a tour de force, and certainly a fine example of science popularization. sions, from antiquity to Einstein, past Kepler, Kant and Kelvin, Cheseaux, Charlier and Fournier d'Albe - with stops at 15 possible solutions to the mystery.
Owen Gingerich is a Professor in the HarvardSmithsonian Center for Astrophysics, 60 Garden Street, Cambridge, Massachusetts 02138, USA. 